\title{
Prevention of chemotherapy-induced nausea and vomiting after high-dose melphalan and stem cell transplantation: review of the evidence and suggestions
}

\author{
Andrea Tendas $^{1}$ (D) . Francesco Marchesi ${ }^{2} \cdot$ Andrea Mengarelli $^{2} \cdot$ Ombretta Annibali $^{3} \cdot$ Valeria Tomarchio $^{3}$. \\ Debora Saltarelli ${ }^{4}$. Anna Chierichini ${ }^{4}$ - Mirko Di Venanzio ${ }^{4}$. Fabio Sollazzo ${ }^{5}$. Monica Piedimonte ${ }^{5}$. Luca Cupelli ${ }^{1}$. \\ Antoine Bruno ${ }^{6}$. Gottardo De Angelis ${ }^{6}$. Luciano Delbono ${ }^{7}$. Pasquale Niscola ${ }^{1}$. Alessio Pio Perrotti ${ }^{1}$. \\ Paolo de Fabritiis ${ }^{1}$ • William Arcese ${ }^{6}$. On behalf of Rome Transplant Network
}

Received: 10 January 2018 / Accepted: 6 December 2018 / Published online: 18 December 2018

(C) Springer-Verlag GmbH Germany, part of Springer Nature 2018

\begin{abstract}
Introduction High-dose melphalan (HDMel) is the most common conditioning chemotherapy regimen for autologous stem cell transplantation (SCT) in patients affected by multiple myeloma (MM). No consensus exists for the emetogenicity or prophylaxis of chemotherapy-induced nausea and vomiting (CINV) in this regimen.

Methods Data on the incidence and efficacy/safety of CINV prophylaxis among patients affected by MM undergoing autologous SCT with the HDMel regimen was extracted from electronic databases and analyzed.

Results Eleven studies involving multiple CINV prophylaxis regimens were identified and included. No consensus on HDMel emetogenicity was reached, but most studies summarized the emetogenicity as moderate-high risk. An aprepitant-based threedrug regimen (aprepitant + serotonin receptor antagonist (5HT3RA) + dexamethasone) showed better efficacy than a two-drug regimen (5HT3RA + dexamethasone) for CINV prevention without increasing the frequency in adverse events.

Conclusions The aprepitant-based three-drug regimen should be the regimen of choice for CINV prophylaxis for MM patients undergoing autologous SCT with HDMel conditioning.
\end{abstract}

Keywords Chemotherapy-induced nausea and vomiting $\cdot$ Stem cell transplantation $\cdot$ High-dose melphalan $\cdot$ Aprepitant $\cdot$ Quality of life

Andrea Tendas

andrea.tendas@aslroma2.it

1 Hematology Division, S. Eugenio Hospital, Piazzale dell'Umanesimo 10, 00144 Rome, Italy

2 Hematology, Regina Elena National Cancer Institute, Rome, Italy

3 Hematology and Stem Cell Transplantation Unit, University Campus Bio-medico, Rome, Italy

4 Hematology, San Giovanni-Addolorata Hospital, Rome, Italy

5 Hematology, Sant'Andrea Hospital, Rome, Italy

6 Hematology, Rome Transplant Network, Department of Hematology, Stem Cell Transplant Unit, Tor Vergata University, Rome, Italy

7 Wake Forest University School of Medicine, Winston Salem, NC, USA

\section{Introduction}

Management of chemotherapy-induced nausea and vomiting (CINV) in high-dose chemotherapy with hemopoietic stem cell transplant (SCT) is challenging $[1,2]$. However, two features identified in this setting should help facilitate CINV management: First, the same conditioning regimens are often used for different diseases, for example, in autologous SCT, BEAM conditioning is used in both Hodgkin and nonHodgkin lymphoma, and in allogenic SCT, conditioning has both a myeloablative and immunosuppressive function. Second, the predominantly inpatient management of SCT facilitates both the monitoring and assessment of CINV.

On the contrary, several aspects make it difficult to understand the mechanism and management of CINV during SCT, which includes the following: (i.) the variability in age, gender, and diagnoses as barriers to epidemiological analysis and evaluation of prophylactic and therapeutic measures; (ii.) the 
fragmentation of available data due to the large amount of bone marrow transplantation units that often perform a limited number of transplants; (iii.) the confounding factors present during HSCT, such as the nausea and vomiting invoked side effect of cryopreservation mean dimethylsulfoxid (DMSO), of cytokines released from infused cells [3], and of supportive therapies, such as antimicrobial prophylaxis or analgesic drugs; (iv.) the limited knowledge about quality of life (QoL) topics, such as CINV, in the practice of SCT and hematology in general; and the (v.) International guidelines suggest the use of the three-drug combination (aprepitant, 5HT3RA, and dexamethasone) in the setting of SCT, but the application of guidelines in multiple days and multiple drugs regimens (commonly used in high-dose chemotherapy conditioning for SCT) is difficult.

However, not all conditioning regimens require multiple days of multiple drug administration. For instance, the highdose melphalan (HDMel) regimen, which is one of the most broadly used, requires either a single day administration of melphalan $200 \mathrm{mg} / \mathrm{sqm}$ (MEL200) or a two-consecutive day administration of melphalan $100 \mathrm{mg} / \mathrm{sqm}$ (MEL100 $\times 2$ ). Thus, HDMel is an ideal testbed for the study of CINV in SCT.

The National Comprehensive Cancer Network (NCCN) guidelines recently placed intravenous melphalan, regardless of the dosage, in the moderately emetogenic category (30$90 \%$ ) [4]. Whereas, the guidelines previously distinguished between doses, placing a melphalan dose less than $50-100 \mathrm{mg} /$ sqm in the low emetogenic risk category (10-30\%) and a melphalan dose greater than $50-100 \mathrm{mg} / \mathrm{sqm}$ in the moderate emetogenic risk category (30-90\%). Another emetogenic classification resource, [5] placed melphalan with a dose greater than $50 \mathrm{mg} / \mathrm{sqm}$ among class 4 drugs (CINV risk 60-90\% [6]).

This data suggests that an increase in dosage correlates with an increase in emetogenicity. In fact, recent literature reports that increasing melphalan dosage from $140 \mathrm{mg} / \mathrm{sqm}$ to $200 \mathrm{mg} / \mathrm{sqm}$ leads to an increase in CINV probability, despite adequate to high-dose prophylaxis [7]. Therefore, in our opinion, the HDMel regimen should be considered from moderate to high emetogenicity. Consequently, CINV prophylaxis should be designed with the three-drug (aprepitant, 5HT3RA, dexamethasone) or four-drug (olanzapine, aprepitant, 5HT3RA, dexamethasone) combinations in accordance with the recommended guidelines for patients undergoing highdose chemotherapy and hemopoietic stem cell transplantation or chemotherapy with high emetogenicity drugs $[4,8,9]$.

\section{Methods}

\section{Review themes}

In this paper, we will review the literature for the emetogenicity and the efficacy and safety of CINV prophylaxis in the HDMel regimen, try to identify the best CINV prophylaxis schedule for HDMel conditioning, examine the safety of the identified schedule in the setting of autologous SCT in multiple myeloma, and provide our recommendation for CINV prophylaxis in this situation.

\section{Search strategy}

Clinical studies reporting on CINV during autologous SCT with HDMel conditioning were included to assess the emetogenicity of HDMel and the efficacy and safety of the antiemetic regimen. The entire PubMed and Google Scholar databases were searched using the following keywords: "chemotherapy-induced nausea and vomiting," "CINV," "nausea," "vomiting," "melphalan," "bone marrow transplantation," "stem cell transplantation," "transplantation," "transplant." Only English language papers were included, and all duplicated studies were removed.

\section{Results}

\section{Results of the search}

Fifteen studies were identified that matched the search criteria. Of the 15,3 were excluded due to patient treatment with multiple conditioning regimens and due to data not reported separately for patients treated with HDMel.

\section{Melphalan emetogenicity during transplants}

Emetogenicity is defined as the capacity of an antineoplastic drug to induce emesis (vomiting or retching). In addition to emesis, an emetogenic drug can induce nausea or anorexia as an adverse effect on gastrointestinal receptors by stimulating conduction routes and central nervous system centers that control nausea and vomiting. The evaluation of emetogenic potential of a certain drug is important because the antiemetic treatment guidelines consider acute emetogenicity, as a criterion for recommendations on CINV prevention [4, 8]. While, for certain drugs, data on emetogenicity are easily available, for other drugs data are still lacking. Melphalan has been in use for nearly 60 years. However, since the phase I trial results are not available in the literature, the data on acute emetogenicity without prophylaxis is unknown. Recently, HDMel toxicity was examined by Abidi MH et al. [10], but the data for acute and delayed emesis was not reported separately. Nevertheless, in the last years, data on the acute and delayed emetogenicity of HDMel were reported in articles that presented the results of clinical trials evaluating the efficacy of new antiemetic drugs. Four detailed articles [11-14] evaluating the acute emetogenicity of HDMel in patients undergoing CINV prophylaxis with different schedules reported a low 
emesis incidence $(0-41 \%)$. Other research on HDMel reported delayed vomiting as moderately frequent (12-66\%), despite adequate prophylaxis [11, 13-16]. Finally, our analysis of the literature showed a similar rate of CINV in the two melphalan schedules (MEL200×1 and MEL100×2).

\section{Efficacy of combination antiemetic therapy}

Eleven papers, reporting results of clinical trials, that explored the effectiveness of a certain prophylaxis for CINV in patients undergoing HDMel conditioning for autologous SCT are included (Table 1). Of these 11 studies, 2 are randomized, comparative, and prospective $[7,18], 6$ are single-arm prospective $[7,12,15,16,18,20], 2$ are comparative and retrospective $[10,19]$, and 1 is single-arm retrospective [13] (Table 1). From these experiments, only aprepitant, fosaprepitant, and olanzapine were compared to standard therapy in the setting of HDMel. There was no data comparing palonosetron or any other drug, such as Nepa, with the standard CINV regimen.

The prospective study by Girault assessed the effects of different palonosetron dosages [11], which is useful for the efficacy and safety of CINV prophylaxis with palonosetron, but not for the comparison of different schedules (Table 1).

The trial by Schmitt [17], comparing a three-drug regimen (aprepitant + granisetron + dexamethasone) with a two-drug regimen (granisetron + dexamethasone), contained 181 patients in each arm. The study was randomized and blinded with placebo administered to patients in the two-drug regimen. The three-drug regimen was significantly more effective especially when comparing emesis. The complete response, which included no emesis or rescue for $0-120 \mathrm{~h}$, in the aprepitant versus placebo was $58 \%$ versus $41 \%$, and the result for no nausea in aprepitant versus placebo was $85 \%$ versus $78 \%$.

The study by Clark SM et al. [18] compared a three-drug regimen, which was administered prospectively, to a historical cohort of patients treated with a two-drug regimen. The threedrug (Fos) aprepitant-containing treatment was more effective when compared to the two-drug 5HT3RA + dexamethasone regimen (see, Table 1). This is similar to the results of the randomized comparative study by Clark SM above.

The retrospective comparative study by Uchida $\mathrm{M}$. et al. [19] was small, $n$ of 48 with only 15 patients treated with HDMel conditioning, and compared a two-drug aprepitant + granisetron against granisetron alone. It is important to note that both regimens were steroid-free. The complete response rate, which involved no vomiting or mentioning of rescue therapy, was $81.8 \%$ in the two-drug aprepitant + granisetron group that had 11 patients compared to $25.0 \%$ in the granisetron only group that had four patients.

The retrospective comparative study by Trifilio S et al. [14] compared an olanzapine-containing triplet therapy with an aprepitant or fosaprepitant-containing triplet therapy. The emesis and nausea control rates were superior for patients treated with the olanzapine-containing regimen (see, Table 1).

The six noncomparative, single-arm, prospective studies $[7,12,15,16,18,20]$ investigated the efficacy of an aprepitant-containing three-drug regimen (four studies [12, $15,16,20])$, a fosaprepitant-containing three-drug regimen (one study [18]), and a palonosetron-containing two-drug regimen (one study [7]). The results disclosed a high probability of protection from emesis with rescue medication (80-88\%) and a lower, although different between trials, probability of protection from emesis without rescue medication (0-52\%).

No trials compared the efficacy of different 5HT3RAs in the setting of HDMel. When analyzing the data of the five trials $[7,11,13,15,20]$ in which palonosetron was used as an 5HT3RA in a two or three-drug regimen, it is impossible to decipher the difference with the other 5HT3RAs (Table 1).

Overall, the (fos)aprepitant-containing three-drug regimen seemed to be superior to the two-drug regimen of 5HT3RA + dexamethasone (Table 1).

\section{Drug-focused overview}

5HT3RA 5HT3RAs are recommended by guidelines for CINV prophylaxis in autologous SCT, as well as for highly emetogenic drugs as part of a three-drug combination (aprepitant + 5HT3RA + dexamethasone) [4, 8, 9]. In the setting of HDMel, palonosetron was investigated in five trials [7, $11,13,15,20]$, granisetron in three trials [12, 17, 19], and ondansetron in three trials $[14,16,18]$. The efficacy of different 5HT3RA drugs was not evaluated in the setting of HDMel; therefore, they should perhaps be considered equivalent in terms of efficacy for CINV prevention.

On the contrary, in terms of safety, palonosetron differs from the other 5HT3RAs. The side effects of 5HT3Rs are well-known. They are frequent and often arise almost acutely, although they are rarely severe [21]. The most important and dangerous side effect is QTc prolongation [22, 23], which can result in arrhythmia, most commonly, tachyarrhythmia, ventricular arrhythmia, and torsade de pointes. This side effect is magnified when 5HT3Rs are administered in patients affected by congenital QTc prolongation syndrome or by electrolytes abnormalities such as hypokalemia and hypomagnesemia. Side effects are also exacerbated when 5HT3Rs are coadministrated with drugs that can affect QT prolongation, such as quinolones, antifungal, and azoles, which are often administered concomitantly during conditioning for autologous transplant. However, in terms of side effects, palonosetron has an advantage, when comparing it with other 5HT3RAs, because it does not cause the QTc prolongation [24] that is common among older generation 5HT3RAs. As such, palonosetron may be preferred over older 5HT3RA agents due to its ability to reduce the risk of QTc prolongation and accompanying arrhythmias. 


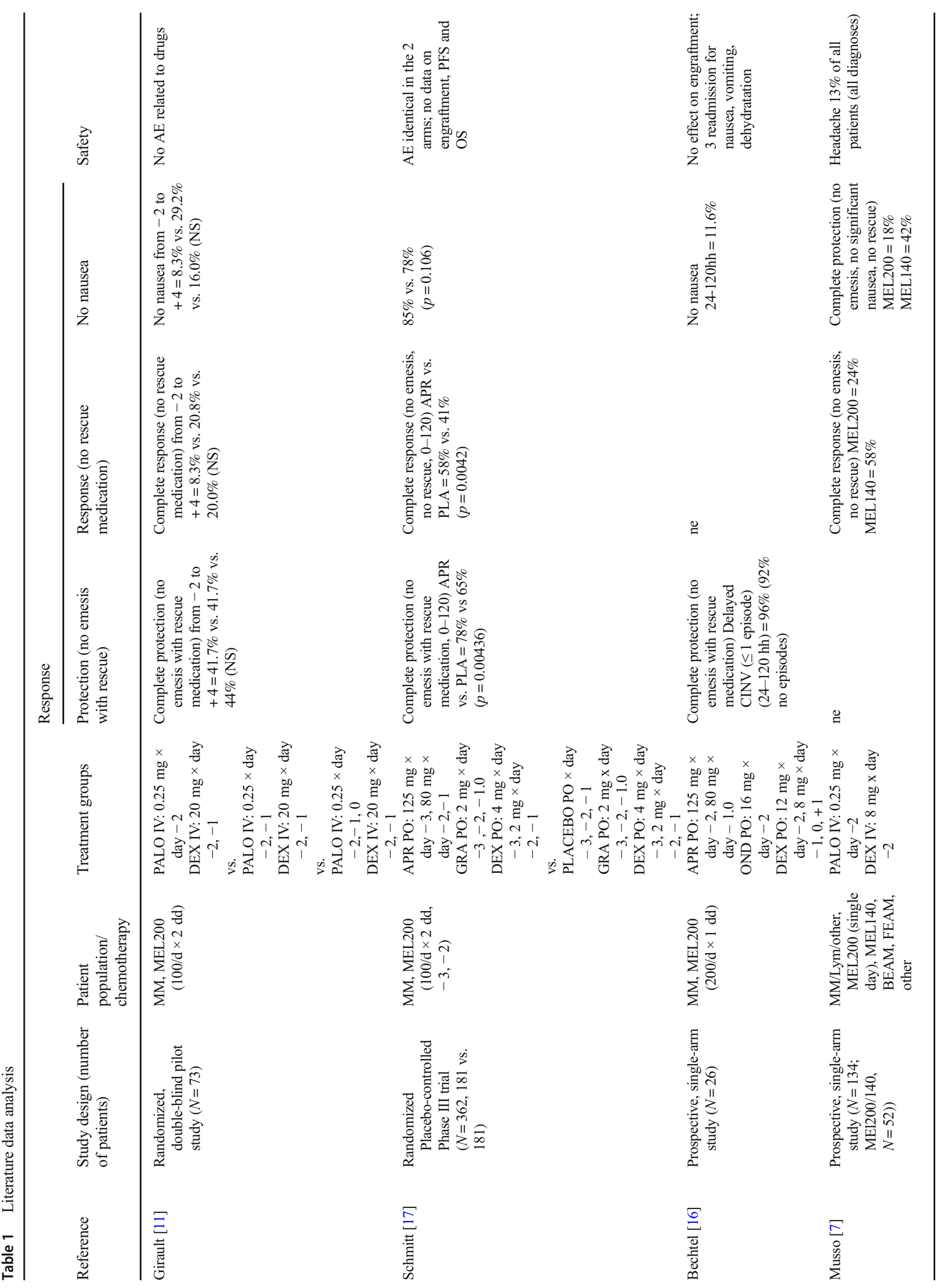




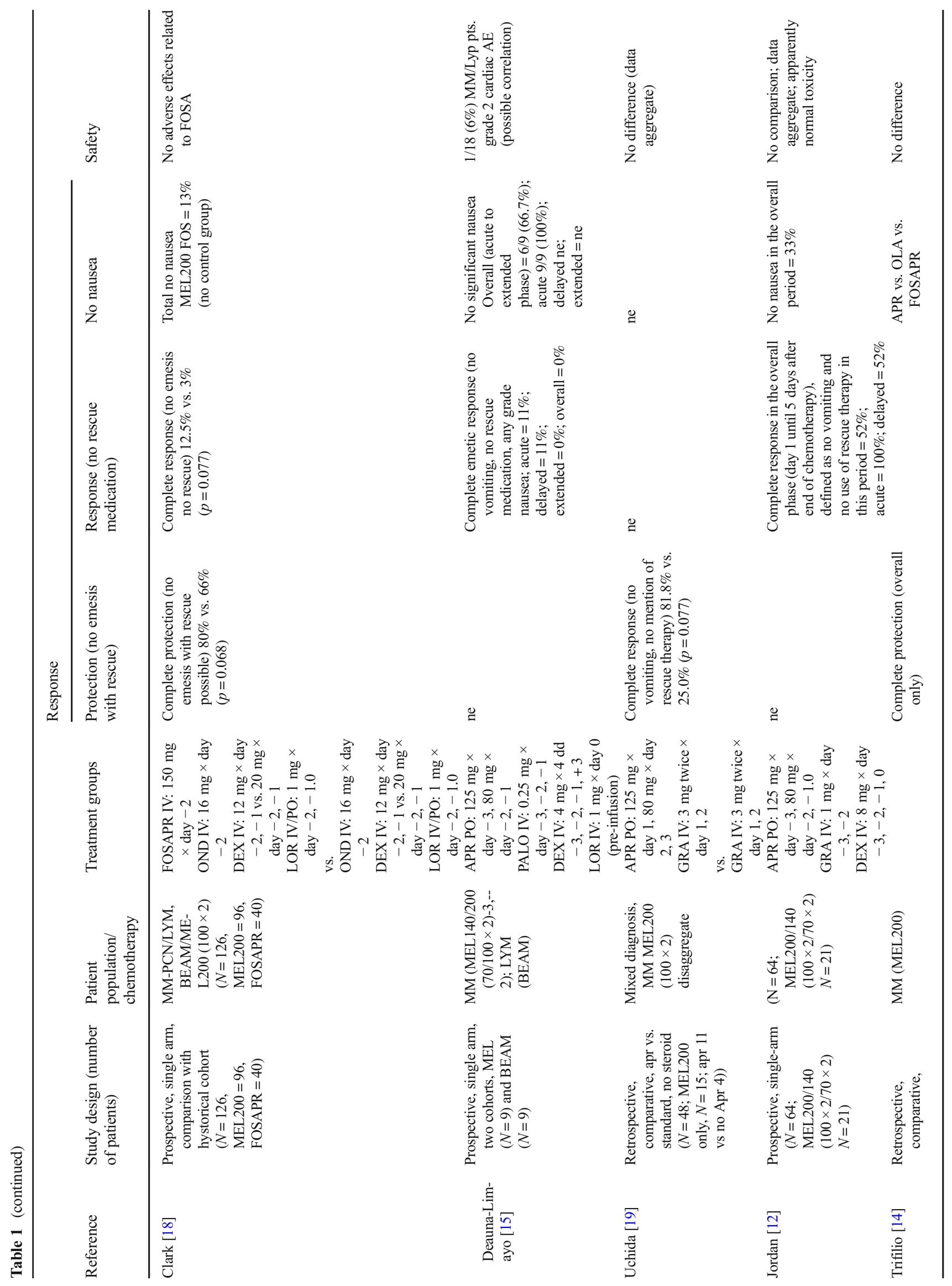




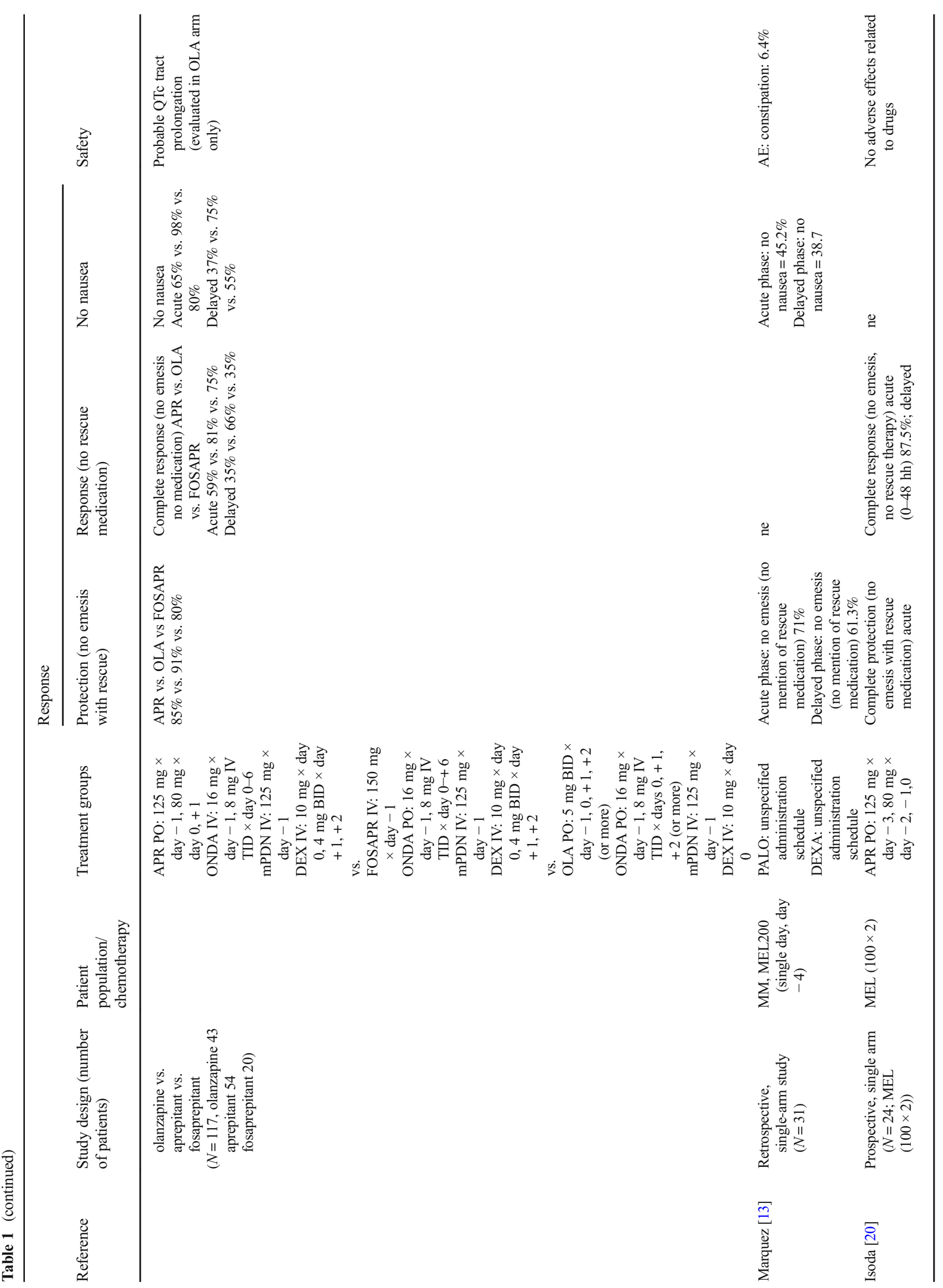




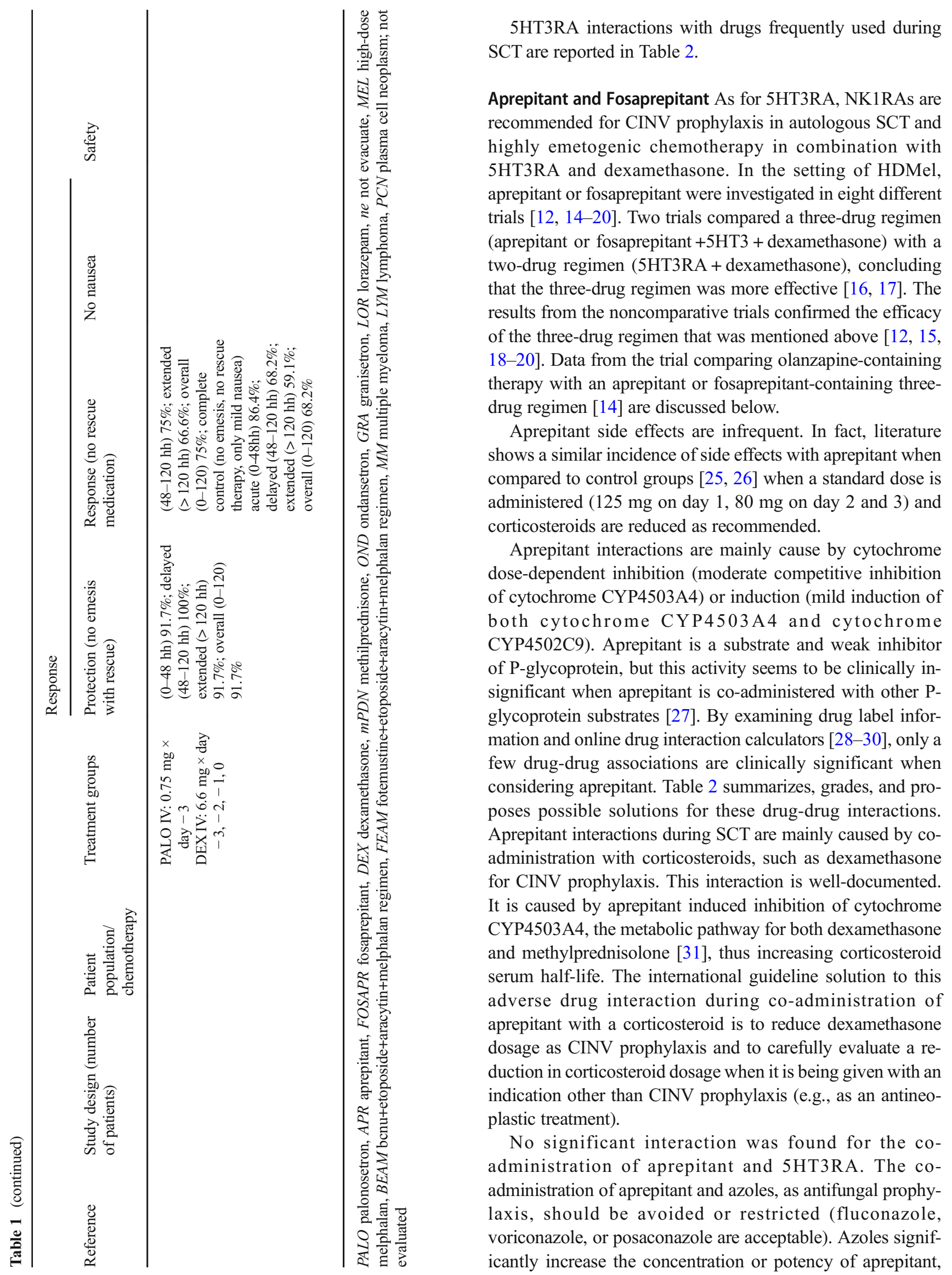


and inversely, aprepitant induces a mild increase in the concentration or potency of itraconazole by affecting hepatic CYP4503A4-mediated metabolism. The interaction between ondansetron and azoles should be avoided or strictly monitored, due to the risk of QTc prolongation and arrhythmias.

The co-administration of aprepitant and proton-pump inhibitors (PPI) should be limited, because PPIs are metabolized by CYP4503A4. However, pantoprazole and omeprazole are considered safe since they are metabolized by different cytochrome isoforms.

The co-administration of aprepitant and quinolones is possible because there is no significant drug-drug interaction. However, quinolones should be used with caution when given with ondansetron and azoles, due to the risk of clinically significant QTc prolongation.

No significant interactions are reported between DMSO or allopurinol and aprepitant.

Corticosteroids Dexamethasone is recommended for CINV prophylaxis in autologous SCT and highly emetogenic chemotherapy in combination with 5HT3RA and (fos)aprepitant. Corticosteroids were co-administered in most trials of CINV prevention in HDMel [7, 11-18, 20], with the exception of one study [19]. From the ten studies that used corticosteroids, dexamethasone was the corticosteroid of choice, used in nine trials $[7,11-13,15-18,20]$, methylprednisolone was used in the remaining trial [14].

The exact mechanism of action of corticosteroids for CINV prevention is unclear, and their use in this setting should be considered off-label. However, guidelines strongly recommend their administration as CINV prophylaxis based on the amount of supportive research data available [4, 8, 32].

The side effects of corticosteroids are well-known. They can be either acute or delayed due to chronic administration [33] (endocrine, neurological/psychiatric, muscle/skeletal [34, 35], immunological [36], etc.). Corticosteroid-induced immunosuppression is directly proportional to the extent of duration and total dose administered, but it is impossible to identify a threshold below which immunosuppression will be absent or clinically insignificant. Therefore, although the duration of administration for CINV prophylaxis is limited, in certain situations, the effect could be relevant and dangerous. For example, in the setting of SCT, patients undergoing high-dose chemotherapy will develop a noteworthy, although transient, immunosuppression due to a decrease in white blood cell count. In this case, any additional immunosuppression could result in an increased risk of infection. This is confirmed by a study that attempted to establish the dose of aprepitant for the prevention of CINV [37]. It was reported that high-dose dexamethasone administered with higher doses of aprepitant caused an increased risk of febrile neutropenia due to CYP3A4-mediated steroid metabolism reduction induced by aprepitant-mediated CYP3A4 inhibition [31]. Based on this interaction, a corticosteroid dosage reduction is recommended whenever aprepitant is co-administered [4, 8].

Corticosteroid interactions with drugs frequently used during SCT are reported in Table 2.

Olanzapine Guidelines for CINV prophylaxis recommend the use of olanzapine in high emetic risk chemotherapy, but not in high-dose chemotherapy with SCT [4, 8, 9]. However, olanzapine is an atypical antipsychotic drug and is currently considered as an off-label treatment for CINV prophylaxis.

The retrospective comparative study by Trifilio S. et al. [14] compared an olanzapine-containing triplet therapy to an aprepitant or fosaprepitant-containing triplet therapy, both in the setting of HDMel. The CINV control rate for the patients treated with the olanzapine-containing regimen was reported as more effective.

The common side effects of olanzapine after short-term administration are sedation, orthostatic hypotension, fatigue, and extrapyramidal disorders $[14,38]$. The potential for interaction between olanzapine and drugs commonly administered during SCT is low (Table 2). Co-administration of olanzapine and metoclopramide increases the risk of adverse neurological events due to antidopaminergic activity, such as extrapyramidal symptoms and neuroleptic malignant syndrome [28-30].

In conclusion, the side effects and drug-drug interactions caused by olanzapine are manageable. Therefore, olanzapine is a potential candidate for CINV prevention in the setting of autologous transplantation. However, its use for CINV prevention is currently off-label; thus, it should not be recommended as a CINV prophylaxis. New prospective comparative trials are warranted to confirm its role as an alternative or partner drug of the NK1RA-containing a three-drug regimen.

\section{Conclusion}

The studies examined in this article provide sufficient data to suggest that the three-drug regimen (NK1RA + 5HT3RA + dexamethasone) is recommended for prevention of CINV in patients undergoing autologous SCT with high-dose melphalan conditioning. The ideal choice of 5HT3RA is palonosetron, due its reduced incidence of cardiac toxicity, such as QTc prolongation, when compared to older generation 5HT3RAs [24]. This is especially the case when other QTcaffecting drugs are co-administered.

The NK1RA of choice is aprepitant (orally) or fosaprepitant (intravenously), since no data exists on the efficacy or safety of different NK1RA drugs in the setting of autologous SCT with HDMel conditioning.

Olanzapine, an atypical antipsychotic drug that is currently not indicated for use in CINV prophylaxis, has common side effects that have the potential to interfere with quality of life. Therefore, olanzapine-containing regimens should be 
Table 2 Clinically significant interactions for aprepitant, olanzapine, setrons and dexamethason with drugs commonly administered during HDMel conditioning for SCT

\begin{tabular}{|c|c|c|}
\hline Aprepitant $<>$ azoles & +++ & $\begin{array}{l}\text { Itraconazole will increase the level or effect of aprepitant by affecting hepatic/intestinal enzyme } \\
\text { CYP3A4 metabolism (competitive inhibition). Avoid or use alternate drug. }\end{array}$ \\
\hline Aprepitant $<>$ azoles & ++ & $\begin{array}{l}\text { Fluconazole, posaconazole and voriconazole will increase the level or effect of aprepitant by } \\
\text { affecting hepatic/intestinal enzyme CYP3A4 metabolism (competitive inhibition). Use } \\
\text { caution/monitor. }\end{array}$ \\
\hline Aprepitant $<>$ azoles & + & $\begin{array}{l}\text { Aprepitant will increase the level or effect of itraconazole by affecting hepatic/intestinal enzyme } \\
\text { CYP3A4 metabolism (competitive inhibition). }\end{array}$ \\
\hline Aprepitant $<>$ azoles & \pm & Aprepitant will slowly induce CYP4503A4 thus potential reducing the level or effect of azoles. \\
\hline Aprepitant $<>$ quinolones & - & No interaction found for levofloxacin and ciprofloxacin \\
\hline Aprepitant $<>$ antiviral agents & - & No interaction found for acyclovir and valaciclovir \\
\hline Aprepitant $<>$ melfalan & - & No interaction found \\
\hline $\begin{array}{l}\text { Aprepitant }<>\text { proton pomp } \\
\text { inhibitors }\end{array}$ & + & $\begin{array}{l}\text { No interaction found for omeprazole and pantoprazole; aprepitant could increase the level or effect } \\
\text { of lansoprazole and rabeprazole by affecting hepatic/intestinal enzyme CYP3A4 metabolism. }\end{array}$ \\
\hline Aprepitant $<>$ 5HT3RAs & - & No interaction found for ondansetron, palonosetron, tropisetron, and granisetron \\
\hline Aprepitant $<>$ corticosteroids & ++ & $\begin{array}{l}\text { Aprepitant will increase the level or effect of dexamethasone and methylprednisolone by inhibition } \\
\text { of CYP3A4-mediated corticosteroids metabolism. Reduce corticosteroids dosage (25-50\%). }\end{array}$ \\
\hline Aprepitant $<>$ corticosteroids & + & $\begin{array}{l}\text { Dexamethasone and methylprednisolone will decrease the level or effect of aprepitant by inducing } \\
\text { hepatic CYP3A4-related aprepitant metabolism. Use caution/monitor. }\end{array}$ \\
\hline Aprepitant $<>$ corticosteroids & \pm & $\begin{array}{l}\text { Aprepitant will slowly induce CYP4503A4 thus potential reducing level or effect of } \\
\text { corticosteroids. }\end{array}$ \\
\hline Aprepitant $<>$ Allopurinol & - & No interaction found \\
\hline $\begin{array}{l}\text { Aprepitant }<>\text { metoclopramide or } \\
\text { olanzapine }\end{array}$ & - & No interaction found for metoclopramide and olanzapine (when used separately) \\
\hline $\begin{array}{l}\text { Olanzapine }<>\text { azoles or } \\
\text { quinolones or antiviral drugs }\end{array}$ & - & No interaction found \\
\hline Olanzapine $<>$ melphalan & - & No interaction found \\
\hline $\begin{array}{l}\text { Olanzapine }<>\text { proton pump } \\
\text { inhibitors }\end{array}$ & - & No interaction found \\
\hline $\begin{array}{l}\text { Olanzapine }<>5 \text { HT3RAs or } \\
\text { corticosteroids }\end{array}$ & - & No interaction found \\
\hline Olanzapine $<>$ Allopurinol & - & No interaction found \\
\hline Olanzapine $<>$ metoclopramide & ++ & $\begin{array}{l}\text { Increased risk of neurological adverse events due to antidopaminergic activity (extrapyramidal } \\
\text { symptoms, neuroleptic malignant syndrome) }\end{array}$ \\
\hline 5HT3RA $<>$ melphalan & - & No interaction found \\
\hline 5HT3RA $<>$ quinolones & ++ & $\begin{array}{l}\text { Moderate risk of QTc elongation and cardiac arrhythmia with ondansetron or tropisetron, low risk } \\
\text { with granisetron; no interaction found with palonosetron }\end{array}$ \\
\hline 5HT3RA $<>$ antiviral drugs & - & No interaction found \\
\hline $\begin{array}{l}\text { 5HT3RA }<>\text { proton pump } \\
\text { inhibitors }\end{array}$ & - & No interaction found \\
\hline 5HT3RA $<>$ azoles & ++ & $\begin{array}{l}\text { Moderate risk of QTc elongation and cardiac arrhythmia with ondansetron, tropisetron, } \\
\text { posaconazole and voriconazole; low risk with granisetron; no interaction found with } \\
\text { palonosetron }\end{array}$ \\
\hline 5HT3RA $<>$ azoles & + & $\begin{array}{l}\text { Itraconazole will increase the level or effect of ondansetron by inhibition of CYP3A4-mediated } \\
\text { ondansetron metabolism. Caution; no dosage reduction needed. }\end{array}$ \\
\hline $\begin{array}{l}\text { 5HT3RA }<>\text { Allopurinol or } \\
\text { metoclopramide }\end{array}$ & - & No interaction found \\
\hline 5HT3RA $<>$ corticosteroids & \pm & $\begin{array}{l}\text { Dexamethasone (but not methylprednisolone) will decrease the level or effect of 5HT3RA by } \\
\text { inducing hepatic CYP3A4-related metabolism. Use caution/monitor. No drug dosages adjust- } \\
\text { ments are needed. }\end{array}$ \\
\hline Corticosteroids $<>$ melphalan & - & No interaction found \\
\hline $\begin{array}{l}\text { Corticosteroids }<>\text { proton pump } \\
\text { inhibitors }\end{array}$ & \pm & $\begin{array}{l}\text { Dexamethasone and methylprednisolone will decrease the level or effect of proton pump inhibitors } \\
\text { by inducing hepatic CYP3A4-related metabolism. Use caution/monitor. No drug dosages ad- } \\
\text { justments are needed. }\end{array}$ \\
\hline $\begin{array}{l}\text { Corticosteroids }<>\text { metoclopramide } \\
\text { or allopurinol }\end{array}$ & - & No interaction found \\
\hline Corticosteroids $<>$ antiviral drugs & - & No interaction found \\
\hline Corticosteroids $<>$ azoles & ++ & $\begin{array}{l}\text { Azoles will increase the level or effect of corticosteroids by inhibition of CYP3A4-mediated } \\
\text { metabolism and P-glycoprotein-mediated efflux. Avoid. }\end{array}$ \\
\hline Corticosteroids $<>$ azoles & \pm & $\begin{array}{l}\text { Corticosteroids will decrease the level or effect of itraconazole by inducing hepatic } \\
\text { CYP3A4-related metabolism. Use caution/monitor. No drug dosages adjustments are needed. }\end{array}$ \\
\hline
\end{tabular}

+++ serious interaction, ++ , moderate interaction, + mild interaction, - no interaction 
Table 3 Suggested schedule as CINV prophylaxis for HDMel conditioning regimen

\begin{tabular}{llll}
\hline & -2 & -1 & 0 \\
\hline Aprepitant & 125 & 80 & 80 \\
5HT3RA & $\mathrm{X}^{*}$ & & \\
Dexamethasone & $4-8 \mathrm{mg}$ & $2-4 \mathrm{mg}$ & $2-4 \mathrm{mg}$ \\
\hline
\end{tabular}

*Palonosetron should be preferred; if other than palonosetron 5HT3RA are administered avoid the co-administration of drugs-inducing QTc prolongation 5HT3RA dosage as for guidelines [4, 5]: ondansetron $8 \mathrm{mg}$ iv; palonosetron $250 \mathrm{mcg}$ iv; granisetron $1 \mathrm{mg}$ iv; tropisetron $5 \mathrm{mg}$ iv; dolasetron $100 \mathrm{mg}$ iv

In any case, avoid the co-administration of azoles and aprepitant

evaluated in prospective clinical trials to adequately assess safety and efficacy in comparison with other standard regimens in the setting of autologous SCT with HDMel conditioning [39].

Currently, there is doubt concerning the risk of steroid therapy in patients undergoing high-dose chemotherapy. For example, despite known corticosteroid ability to help treat multiple myeloma, it is rarely administered during HDMel active therapy due to the potential risk of infectious complications. This concern is also palpable in general practice where hematologists are reluctant to administer steroids. Therefore, in the setting of transplant, our opinion is to limit the usage of corticosteroids, because the value lost in steroids-free CINV prophylaxis [32] should be contained by NK1 antagonist or new generation 5HT3RA, such as palonosetron. The suggested schedule is stated in Table 3.

A limitation of this review arises from the heterogeneity of the studies examined. An example is the administration of different HDMel regimens, MEL100 $\times 2$ and MEL200, which contain potentially different effects on CINV probability. However, we do not believe this is a limitation that invalidates our conclusion. Instead, it emphasizes the necessity to standardize the management of patients undergoing SCT, even in the setting of ameliorative care, such as CINV prophylaxis.

Continuous monitoring on the efficacy and safety of the three-drug regimen that is suggested above for the prophylaxis of CINV in autologous SCT after HDMel conditioning will be essential not only to expand on the availability of data that supports this regimen but also to encourage its use with different conditioning regimes and in allogeneic transplantations.

\section{Compliance with ethical standards}

Conflict of interest The authors declare that they have no conflict of interest.

Publisher's Note Springer Nature remains neutral with regard to jurisdictional claims in published maps and institutional affiliations.

\section{References}

1. Tendas A, Niscola P, Perrotti A, Dentamaro T, de Fabritiis P, Arcese W, Rome Transplant Network (RTN) Quality of Life Working Party (2015) Chemotherapy induced nausea and vomiting in bone marrow transplant: the unmet need. Support Care Cancer 23(8):2211. https://doi.org/10.1007/s00520-015-2711-z

2. Tendas A, Sollazzo F, Bruno A, Cupelli L, Niscola P, Pignatelli AC, Dentamaro T, de Fabritiis P, Arcese W (2012) Obstacles to managing chemotherapy-induced nausea and vomiting in high-dose chemotherapy with stem cell transplant. Support Care Cancer 20(5): 891-892. https://doi.org/10.1007/s00520-012-1411-1

3. Cox MA, Kastrup J, Hrubiško M (2012) Historical perspectives and the future of adverse reactions associated with haemopoietic stem cells cryopreserved with dimethyl sulfoxide. Cell Tissue Bank 13(2):203-215

4. NCCN guidelines NCCN Clinical Practice Guidelines in Oncology (NCCN Guidelines ${ }^{\circledR}$ ) Antiemesis. Version 3.2018; https://www. nccn.org/professionals/physician_gls/pdf/antiemesis.pdf. Accessed 15 Jan 2018

5. Oncology Nursing Society ONS. Emetogenic Risk Of Chemotherapy and Biotherapy Agents. https://www.ons.org/sites/ default/files/emetogenicity tool.pdf. Accessed 15 Jan 2018

6. Hesketh PJ (1999) Defining the emetogenicity of cancer chemotherapy regimens: relevance to clinical practice. Oncologist 4(3): 191-196

7. Musso M, Scalone R, Crescimanno A, Bonanno V, Polizzi V, Porretto F, Bianchini C, Perrone T (2010) Palonosetron and dexamethasone for prevention of nausea and vomiting in patients receiving high-dose chemotherapy with auto-SCT. Bone Marrow Transplant 45(1):123-127. https://doi.org/10.1038/bmt.2009.114

8. Roila F, Molassiotis A, Herrstedt J, Aapro M, Gralla RJ, Bruera E, On behalf of the participants of the MASCC/ESMO Consensus Conference Copenhagen 2015 et al (2016) MASCC and ESMO Consensus Guidelines for the Prevention of Chemotherapy and Radiotherapy-Induced Nausea and Vomiting: ESMO Clinical Practice Guidelines. Ann Oncol 27(suppl 5):v119-v133

9. Herrstedt J, Roila F, Warr D, Celio L, Navari RM, Hesketh PJ, Chan A, Aapro MS (2017) 2016 Updated MASCC/ESMO consensus recommendations: prevention of nausea and vomiting following high emetic risk chemotherapy. Support Care Cancer 25(1):277288

10. Abidi MH, Agarwal R, Tageja N, Ayash L, Deol A, Al-Kadhimi Z, Abrams J, Cronin S, Ventimiglia M, Lum L, Ratanatharathorn V, Zonder J, Uberti J (2013) A phase I dose-escalation trial of highdose melphalan with palifermin for cytoprotection followed by autologous stem cell transplantation for patients with multiple myeloma with normal renal function. Biol Blood Marrow Transplant 19(1):56-61. https://doi.org/10.1016/j.bbmt.2012.08.003

11. Giralt SA, Mangan KF, Maziarz RT, Bubalo JS, Beveridge R, Hurd DD, Mendoza FL, Rubenstein EB, DeGroot TJ, Schuster MW (2011) Three palonosetron regimens to prevent CINV in myeloma patients receiving multiple-day high-dose melphalan and hematopoietic stem cell transplantation. Ann Oncol 22(4):939-946. https:// doi.org/10.1093/annonc/mdq457

12. Jordan K, Jahn F, Jahn P, Behlendorf T, Stein A, Ruessel J, Kegel T, Schmoll HJ (2011) The NK-1 receptor-antagonist aprepitant in high-dose chemotherapy (high-dose melphalan and high-dose TICE: paclitaxel, ifosfamide, carboplatin, etoposide): efficacy and safety of a triple antiemetic combination. Bone Marrow Transplant 46(6):784-789. https://doi.org/10.1038/bmt.2010.205

13. Marquez AMG, Vazquez LC, Fernandez CAS, Moral JLS (2017) Revision of nausea and vomiting in patients with haematological malignancies and hematopoietic transplantation. Hematol Transfus Int J 4(3):00085 
14. Trifilio S, Welles C, Seeger K, Mehta S, Fishman M, McGowan K, Strejcek K, Eiten E, Pirotte C, Lucier E, DeFrates S, Mehta J (2017) Olanzapine reduces chemotherapy-induced nausea and vomiting compared with aprepitant in myeloma patients receiving highdose melphalan before stem cell transplantation: a retrospective study. Clin Lymphoma Myeloma Leuk 17(9):584-589

15. Deauna-Limayo D, Aljitawi OS, Ganguly S, Abhyankar S, Wick JA, McGuirk JP (2014) Combined use of multiday palonosetron with aprepitant and low-dose dexamethasone in prevention of nausea and emesis among patients with multiple myeloma and lymphoma undergoing autologous hematopoietic stem cell transplant: a pilot study. J Oncol Pharm Pract 20(4):263-269. https://doi.org/ 10.1177/1078155213502103

16. Bechtel T, McBride A, Crawford B, Bullington S, Hofmeister CC, Benson DM Jr, Jaglowski S, Penza S, Andritsos LA, Devine SM (2014) Aprepitant for the control of delayed nausea and vomiting associated with the use of high-dose melphalan for autologous peripheral blood stem cell transplants in patients with multiple myeloma: a phase II study. Support Care Cancer 22(11):2911-2916. https://doi.org/10.1007/s00520-014-2248-6

17. Schmitt T, Goldschmidt H, Neben K, Freiberger A, Hüsing J, Gronkowski M, Thalheimer M, Pelzl le H, Mikus G, Burhenne J, Ho AD, Egerer G (2014) Aprepitant, granisetron, and dexamethasone for prevention of chemotherapy-induced nausea and vomiting after high-dose melphalan in autologous transplantation for multiple myeloma: results of a randomized, placebo-controlled phase III trial. J Clin Oncol 32(30):3413-3420. https://doi.org/10.1200/JCO. 2013.55.0095

18. Clark SM, Clemmons AB, Schaack L, Garren J, DeRemer DL, Kota VK (2016) Fosaprepitant for the prevention of nausea and vomiting in patients receiving BEAM or high-dose melphalan before autologous hematopoietic stem cell transplant. J Oncol Pharm Pract 22(3):416-422. https://doi.org/10.1177/1078155215585190

19. Uchida M, Ikesue H, Miyamoto T, Kato K, Suetsugu K, Ichinose K, Hiraiwa H, Sakurai A, Takenaka K, Muta T, Iwasaki H, Teshima T, Shiratsuchi M, Egashira N, Akashi K, Oishi R (2013) Effectiveness and safety of antiemetic aprepitant in Japanese patients receiving high-dose chemotherapy prior to autologous hematopoietic stem cell transplantation. Biol Pharm Bull 36(5):819-824

20. Isoda A, Saito R, Komatsu F, Negishi Y, Oosawa N, Ishikawa T, Miyazawa Y, Matsumoto M, Sawamura M, Manaka A (2017) Palonosetron, aprepitant, and dexamethasone for prevention of nausea and vomiting after high-dose melphalan in autologous transplantation for multiple myeloma: a phase II study. Int J Hematol 105(4):478-484. https://doi.org/10.1007/s12185-016-2152-6

21. Goodin S, Cunningham R (2002) 5-HT(3)-receptor antagonists for the treatment of nausea and vomiting: a reappraisal of their sideeffect profile. Oncologist 7(5):424-436

22. Navari RM, Koeller JM (2003) Electrocardiographic and cardiovascular effects of the 5-hydroxytryptamine 3 receptor antagonists. Ann Pharmacother 37(9):1276-1286

23. Zofran Label - FDA. U.S Food and Drug Administration website. https://www.accessdata.fda.gov/drugsatfda_docs/label/2016/ 020103s035_020605s019_020781s019lbl.pdf. Accessed 15 Jan 2018

24. Gonullu G, Demircan S, Demirag MK, Erdem D, Yucel I (2012) Electrocardiographic findings of palonosetron in cancer patients.
Support Care Cancer 20(7):1435-1439. https://doi.org/10.1007/ s00520-011-1226-5

25. Emend Label - FDA. U.S Food and Drug Administration website. http://www.accessdata.fda.gov/drugsatfda_docs/label/2009/ 021549s016lbl.pdf. Accessed 15 Jan 2018

26. Rapoport BL, Jordan K, Boice JA, Taylor A, Brown C, Hardwick JS, Carides A, Webb T, Schmoll HJ (2010) Aprepitant for the prevention of chemotherapy-induced nausea and vomiting associated with a broad range of moderately emetogenic chemotherapies and tumor types: a randomized, double-blind study. Support Care Cancer 18(4):423-431. https://doi.org/10.1093/annonc/mdq149 Review

27. Feuring M, Lee Y, Orlowski LH, Michiels N, De Smet M, Majumdar AK, Petty KJ, Goldberg MR, Murphy MG, Gottesdiener KM, Hesney M, Brackett LE, Wehling M (2003) Lack of effect of aprepitant on digoxin pharmacokinetics in healthy subjects. J Clin Pharmacol 43(8):912-917

28. Multidrug interaction checker - Medscape Reference. http:// reference.medscape.com/drug-interactionchecker. Accessed 15 Jan 2018

29. Drug interaction - WebMD. http://www.webmd.com/interactionchecker/. Accessed 15 Jan 2018

30. Drug interactions checker - For drugs, foods and alcohol - Drugs. com. https://www.drugs.com/drug_interactions.html. Accessed 15 Jan 2018

31. Aapro MS, Walko CM (2010) Aprepitant: drug-drug interactions in perspective. Ann Oncol 21(12):2316-2323

32. Grunberg SM (2007) Antiemetic activity of corticosteroids in patients receiving cancer chemotherapy: dosing, efficacy, and tolerability analysis. Ann Oncol 18(2):233-240

33. Decadron - FDA. U.S Food and Drug Administration website. http://www.accessdata.fda.gov/drugsatfda_docs/label/2004/ 11664slr062_decadron_lbl.pdf. Accessed 15 Jan 2018

34. Schakman $\bar{O}$, Gilson H, Thissen JP (2008) Mechanisms of glucocorticoid-induced myopathy. J Endocrinol 197(1):1-10. https://doi.org/10.1677/JOE-07-0606

35. Decramer M, Lacquet LM, Fagard R, Rogiers P (1994) Corticosteroids contribute to muscle weakness in chronic airflow obstruction. Am J Respir Crit Care Med 150:11-16

36. Fardet L, Petersen I, Nazareth I (2016) Common infections in patients prescribed systemic glucocorticoids in primary care: a population-based cohort study. PLoS Med 13(5):e1002024. https://doi.org/10.1371/journal.pmed.1002024

37. Chawla SP, Grunberg SM, Gralla RJ, Hesketh PJ, Rittenberg C, Elmer ME, Schmidt C, Taylor A, Carides AD, Evans JK, Horgan KJ (2003) Establishing the dose of the oral NK1 antagonist aprepitant for the prevention of chemotherapy-induced nausea and vomiting. Cancer 97(9):2290-2300

38. Zyprexa Label - FDA. U.S Food and Drug Administration website. https://www.accessdata.fda.gov/drugsatfda_docs/label/2009/ 020592s051,021086s030,021253s0361bl.pdf. Accessed 15 Jan 2018

39. Tendas A, Marchesi F, Annibali O, Saltarelli D, Niscola P, Perrotti AP, Arcese W (2018) Chemotherapy induced nausea and vomiting prophylaxis in high-dose melphalan and autologous stem cell transplantation. Clin Lymphoma Myeloma Leuk Article in Press. https:// doi.org/10.1016/j.clml.2017.12.001 